\title{
Relation between body mass index and depression: a structural equation modeling approach Alina Dragan ${ }^{1}$ and Noori Akhtar-Danesh*2
}

\author{
Address: ${ }^{1}$ Nursing Health Services Research Unit, McMaster University, Canada and ${ }^{2}$ School of Nursing and Department of Clinical Epidemiology \\ \& Biostatistics, McMaster University, Canada \\ Email: Alina Dragan - dragana@mcmaster.ca; Noori Akhtar-Danesh* - daneshn@mcmaster.ca \\ * Corresponding author
}

Published: 30 April 2007

BMC Medical Research Methodology 2007, 7:17 doi:10.1186/147|-2288-7-17

This article is available from: http://www.biomedcentral.com/I47/-2288/7//7

(C) 2007 Dragan and Akhtar-Danesh; licensee BioMed Central Ltd.

This is an Open Access article distributed under the terms of the Creative Commons Attribution License (http://creativecommons.org/licenses/by/2.0), which permits unrestricted use, distribution, and reproduction in any medium, provided the original work is properly cited.

\begin{abstract}
Background: Obesity and depression are two major diseases which are associated with many other health problems such as hypertension, dyslipidemia, diabetes mellitus, coronary heart disease, stroke, myocardial infarction, heart failure in patients with systolic hypertension, low bone mineral density and increased mortality. Both diseases share common health complications but there are inconsistent findings concerning the relationship between obesity and depression. In this work we used the structural equation modeling (SEM) technique to examine the relation between body mass index (BMI), as a proxy for obesity, and depression using the Canadian Community Health Survey, Cycle I.2.
\end{abstract}

Methods: In this SEM model we postulate that I) BMI and depression are directly related, 2) BMI is directly affected by the physical activity and, 3)depression is directly influenced by stress. SEM was also used to assess the relation between BMI and depression separately for males and females.

Results: The results indicate that higher BMI is associated with more severe form of depression. On the other hand, the more severe form of depression may result in less weight gain. However, the association between depression and BMI is gender dependent. In males, the higher BMI may result in a more severe form of depression while in females the relation may not be the same. Also, there was a negative relationship between physical activity and BMI.

Conclusion: In general, use of SEM method showed that the two major diseases, obesity and depression, are associated but the form of the relation is different among males and females. More research is necessary to further understand the complexity of the relationship between obesity and depression. It also demonstrated that SEM is a feasible technique for modeling the relation between obesity and depression.

\section{Background}

Obesity and depression are two major diseases associated with numerous health complications [1]. Obesity is linked with hypertension, dyslipidemia, diabetes mellitus, coronary heart disease, stroke, as well as increased all cause mortality [2]. Depression contributes to increased risk of coronary heart disease, myocardial infarction, heart failure in patients with systolic hypertension, low bone mineral density, and increased mortality [3-8]. 
Both diseases share common health complications but there is inconsistent findings concerning the relationship between obesity and depression. Some studies concluded that there was no relation between obesity and depression $[9,10]$, while others reported that obese people had higher risk of depression $[11,12]$ or that heavier people were less depressed [13,14]. Goodman and Whitaker [15] showed that depressed adolescents are at increased risk for the development and persistence of obesity later in their life and Pine et al. [16] concluded that depression in childhood was positively associated with BMI during adulthood. In spite of the inconsistent findings overall it is believed that psychological distresses caused by obesity may lead to depression [17]. Other researchers, for instance Rosmond [18], have even suggested that obesity and depression might be the same disease with different manifestations. The relation between obesity and depression could depend on factors such as sex, level of obesity, level of depression, socio-economic status and family history of depression [17].

In this article we used the structural equation modeling (SEM) technique to assess the relation between BMI (as a proxy for obesity) and depression in a sample of 12,376 individuals from the province of Ontario as a subset of the 2002 Canadian Community Health Survey, Cycle 1.2 (CCHS-1.2) dataset. The main objective was to examine the potential of the SEM technique for such complex analysis. This sample size is large enough to disentangle the complexity of the relation between obesity and depression. In addition, the results could be used as an approximation for Canadian population given that Ontario represents about $40 \%$ of the total Canadian population [19].

\section{Methods \\ Data source}

The CCHS-1.2 is a cross-sectional survey that contains information related to health status, health care utilization and health determinants for the Canadian population. The survey is based on a complex design, with stratification and multiple stages of selection, and unequal probabilities of selection to ensure adequate representation of young persons (15 to 24 years) and seniors (65 years and over) [20]. The questionnaire was administered on the sample units selected from the area frames using the computer-assisted interviewing (CAI) method. One person aged 15 years and over was randomly selected from the sampled households. The dataset contains information from 36,984 individuals with a response rate of $77.0 \%$ in Canada of which 12,376 respondents were from Ontario. There were 76 pregnant women who were excluded from the analysis.

\section{Variables}

The following variables have been suggested in the literature to be associated with the relation between depression and obesity:

\section{Body mass index (BMI)}

The CCHS-1.2 survey used the respondents' self-reported measurements of height and weight to calculate the body mass index (BMI) which is an index of weight-to-squared height $\left(\mathrm{kg} / \mathrm{m}^{2}\right)$. In this analysis BMI has been used as a continuous variable as reported in the dataset.

\section{Depression}

Persistence of Major Depressive Episode is a continuous variable that identifies the longest period associated with a major depressive episode experienced by the respondent. We used this variable as the main proxy for depression.

\section{Physical activity}

To derive a physical activity index, the energy expenditure (EE) of participants in their leisure activities was estimated using the frequency and time per physical activity session as well as the metabolic energy cost (MET) value. This value is expressed as a multiple of the resting metabolic rate $[21,22]$. In this survey respondents were asked to specify the intensity level of their activities; therefore the MET values adopted correspond to the low intensity value of each activity.

\section{Stress management}

This variable was approximated by ability to handle unexpected and difficult problems in the dataset. Participants were asked to rate their ability in handling unexpected and difficult problems such as a family or personal crisis on a 5-point Likert scale from excellent to poor so that higher scores relate to decreased ability in handling unexpected and difficult problems.

\section{Socioeconomic status (SES)}

Socioeconomic status is frequently measured by job status, income, and education $[23,24]$. We used a factor analysis technique to extract a latent variable from the variables of job status during the past year, multiple job status, income per household, income per person, and education. As a result, education did not load significantly on the factor; therefore, we removed it and made the SES factor with the other four variables.

Eating habits - eating attitudes test (EAT) index

This variable measures the extent of the symptoms and concerns characteristic of eating disorders [25]. Higher scores of EAT index indicate higher risk of eating disorder. 


\section{Relatives with depression}

This variable is a measure of the number of close relatives, including biological parents, siblings, and children who ever had at least one episode of being depressed.

\section{Statistical analysis}

The structural equation modeling is a method for representing, estimating and testing a theoretical network of mostly linear relations between variables that may be either directly observable or unobservable and may only be measured imperfectly. It is a generalization of both regression and factor analysis and comprises most of the linear modeling methods as "special cases". The procedure places emphasis on covariance structures rather than cases. The fundamental hypothesis in using SEM is that the covariance matrix of the observed variables is a function of a set of parameters. If the model is correct and the parameters are known, then the population covariance matrix would be exactly reproduced by SEM (except for sampling variation). SEM proceeds by assessing whether a sample covariance or correlation matrix is consistent with a hypothetical matrix implied by the model. The inputs are either raw data or sample moments computed from the data, and a model to be evaluated. The sample moments will include either correlations or variances and covariances. It may also include means and higher order moments [26].

The general SEM model can be decomposed into two submodels: a measurement model and a structural model. The measurement model defines relations between the observed and unobserved latent variables. The structural model defines relations among the unobserved variables by specifying the pattern by which particular latent variables directly or indirectly influence some other latent variables in the model.

SEM is mainly a confirmatory technique rather than exploratory and is more likely to be used to determine whether a certain model is valid, rather than to find a suitable model. However, SEM analysis often involves a certain degree of exploratory analysis. By convention, when graphically representing the model the observed variables are enclosed by rectangles or squares and latent variables are enclosed by ovals or circles. Residuals are always unobserved and are represented by ovals or circles.

In this work to evaluate the goodness-of-fit of a model the root mean square error of approximation (RMSEA) statistic and the comparative fit index (CFI) were used as these are the most commonly used indices [26]. The RMSEA estimates the lack of fit in a model compared to a saturated model. The estimated RMSEA is given by:

$$
\text { estimated RMSEA }=\sqrt{\frac{\hat{F}_{0}}{d f_{\text {model }}}}
$$

where $\hat{F}_{0}=\operatorname{Max}\left(\frac{\chi_{\text {model }}^{2}-d f_{\text {model }}}{N}, 0\right)$ and $N$ is the sample size [27]. For a perfect model $\hat{F}_{0}=0$. Values of RMSEA of 0.06 or less indicate a good-fitting model and a value larger than 0.10 is indicative of a poor model.

The comparative fit index (CFI) assesses fit relative to other models. It employs the noncentral $\chi^{2}$ distribution with noncentrality parameters, $\tau_{i}$. The larger $\tau_{i}$ indicates the greater model misspecification. For a perfect model $\tau_{i}=0$. The CFI is defined as:

$$
\mathrm{CFI}=1-\frac{\tau_{\text {model }}}{\tau_{\text {indep }}}
$$

with

$$
\tau_{\text {indep }}=\chi_{\text {indep }}^{2}-d f_{\text {indep }} \text { and } \tau_{\text {model }}=\chi_{\text {model }}^{2}-d f_{\text {model }} \text {. }
$$

The parameter $\tau_{\text {indep }}=\chi_{\text {indep }}^{2}-d f_{\text {indep }}$ refers to the independence model which assumes zero population covariances among the observed variables [28]. CFI values greater than 0.90 indicate reasonably good fit of the model [29]. The analysis were performed using the AMOS software [30].

\section{The Stunkard model}

Stunkard et al. [31] suggested a model which encompasses a "genetic correlation" and an "environmental correlation" between depression and obesity. The "genetic correlation" refers to the likelihood that there might be a set of genes that promote both depression and obesity, while the "environmental correlation" underlines the possibility of existence of "common life experiences" that may promote both diseases. Although this model does not completely explain the physiological pathways between the two diseases, it has been used as an empirical framework in studies of genetic epidemiology [32].

We started the analysis with an adaptation of Stunkard's model. This model consists of two unobserved latent variables of Environ (for environment) and Genes and eight observed variables (Figure 1). The observed variables load on the latent variables (factors) in the following pattern: 


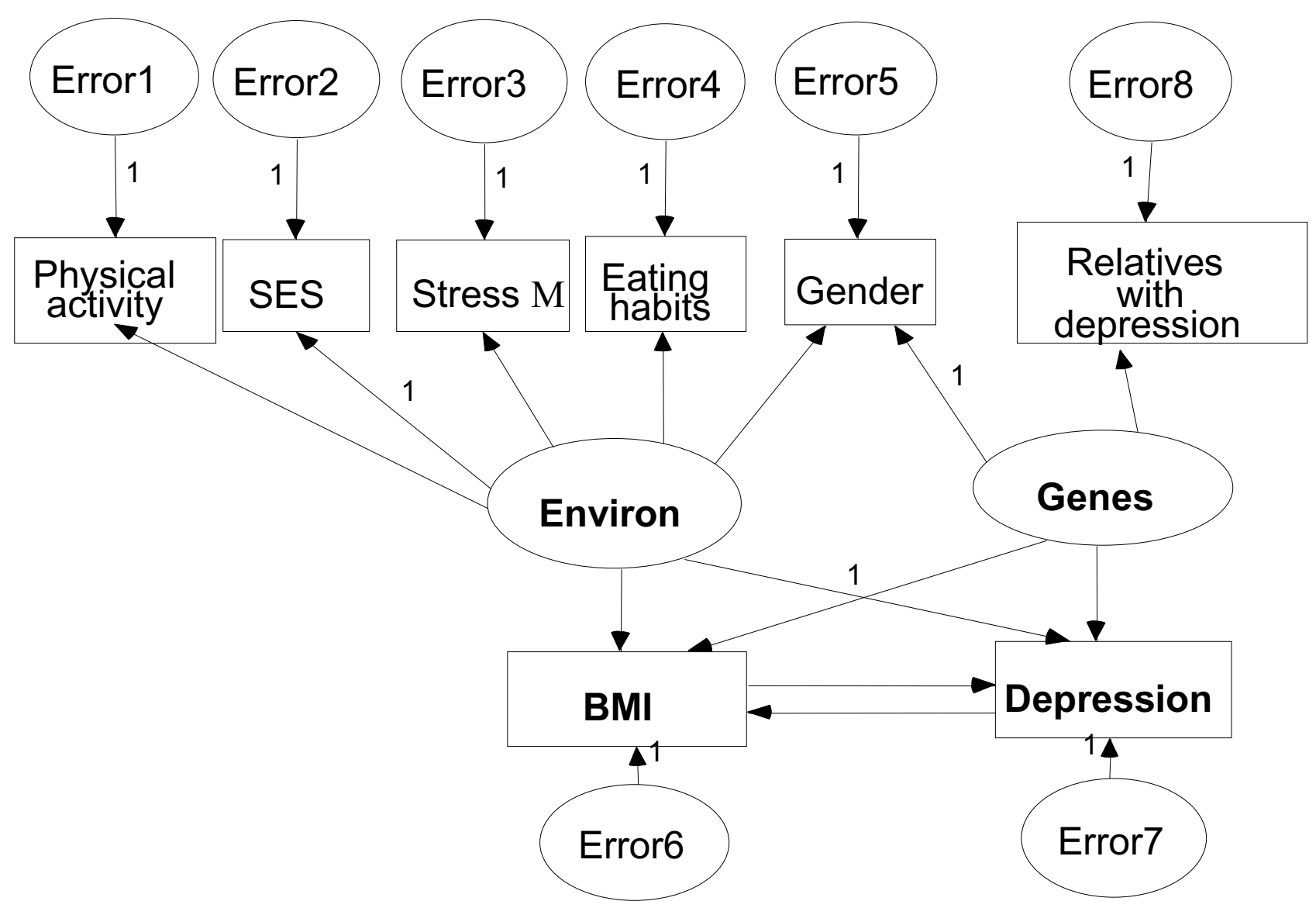

Figure I

Model I - SEM model with two latent variables of Environ and Genes (Stress $M=$ Stress Management).

a) Physical activity, SES, stress management, eating habits and gender which are usually considered as the components of the environment load on the first factor, Environ.

b) Gender and relatives with depression load on the second factor, Genes.

c) Both BMI and depression regress on the aforementioned factors.

Measurement errors associated with each observed variable were added with the assumption that these error terms were independent from each other.

This hypothesized model is a non-recursive model, that is, it is a model with two structural equations where the dependent variable of each equation appears as a predictor variable in the other equation. In this model BMI and depression form a feedback loop; meaning that we can follow the path between these two variables on an infinite number of times without having to return to the other variables. This model states that BMI is directly influenced by depression and vice versa.

\section{Results}

A summary of descriptive statistics is given in Table 1. As this table shows about 50 percent of Ontarian suffer from overweight or obesity and approximately 12 percent of the respondents reported experiencing some period of major depressive episode. In this dataset variables of eating habit and relatives with depression have large numbers of missing values.

Of great importance in SEM is the extent to which the hypothesized model fits the dataset. Using SEM technique, Model 1 (see Figure 1) had values less than the minimum acceptable level and the goodness-of-fit indices proved not to be a good fit to the dataset. In particular, it showed that Genes is not a good construct of gender and relatives with depression. 
Table I: Descriptive statistics of variables used in the analysis

\begin{tabular}{|c|c|c|c|c|c|}
\hline Variables & $\mathbf{N}(\%)$ & Mean & Std. Deviation & Min & Max \\
\hline Gender & 12376 & - & - & - & - \\
\hline Males & $5660(45.3)$ & - & - & - & - \\
\hline Females & $6716(54.3)$ & - & - & - & - \\
\hline Body Mass Index & $10961 \S$ & 25.75 & 4.84 & 9.60 & 57.80 \\
\hline Under/Normal weight & 5449 (49.7) & - & - & - & - \\
\hline Overweight & $3710(33.8)$ & - & - & - & - \\
\hline Obese & $1802(16.4)$ & - & - & - & - \\
\hline Depression (\# years with MDE-lifetime) & $12282^{\S}$ & 0.41 & 8.20 & 0 & 67.00 \\
\hline No depression ( 0 years) & $10826(88.1)$ & - & - & - & - \\
\hline Yes depression & $1456(11.9)$ & - & - & - & - \\
\hline Physical Activity & $12375 \S$ & 2.27 & 2.34 & 0 & 28.70 \\
\hline Stress Management & $12352 \S$ & 2.31 & 0.93 & I & 5 \\
\hline Eating Habits & $1812^{\S}$ & 10.63 & 8.85 & 0 & 62 \\
\hline Relatives with Depression & $1512 \S$ & 1.76 & 3.02 & 0 & 55 \\
\hline
\end{tabular}

$\S$ the number is different from the total of 12376 because of missing values

In an effort to improve the model the variable relatives with depression was eliminated due to large numbers of missing data and the connection between gender and depression was dropped due to its non-significant path (Model 2). However, these changes did not improve the model satisfactorily. Consequently the resulting third model had one latent variable, Environ, with gender connected to it directly. The model contained 6 observed variables: physical activity, SES, stress management, gender, BMI and depression and one latent variable, Environ. In this third model it was hypothesized that $B M I$ is directly affected by physical activity and depression is directly influenced by stress, as previously reported in the literature [33].

For this model the estimated RMSEA is 0.047 with the $90 \%$ confidence interval of $(0.040,0.054)$ and the $p$-value for the test of closeness of fit of 0.776 . The interpretation of the confidence interval indicates that with $90 \%$ confidence the true RMSEA value in the population falls within the bounds of 0.040 and 0.054 , and therefore represents a good degree of precision. Given that the upper bound of the $90 \%$ confidence interval is less than the suggested value of 0.06 [34], and the probability value associated with this test of close fit is $>0.50$ (i.e. 0.776), it can be concluded that the hypothesized model fits the data well. In addition, the CFI value is 0.898 which indicates an acceptable level for model fitting. Also, the factor loadings and path coefficients for this model are significantly different from zero and there is no near-zero standard errors for the factor loadings and path coefficients (Table 2). Of great interest in the analysis are the path coefficients that constitute the structural portion of the model. The path coefficients for the path from BMI to depression, from depression to BMI, from Environ to BMI and Environ to depression are all significant. In addition, AMOS estimates a stability index for each model. An index value between -1 and 1 indicates a stable model [26]. For Model 3 a stability index of 0.042 indicates that the system is indeed stable.

\section{Subgroup analysis}

Model 3 indicates that there is a relationship between BMI and depression and the effect of gender on this relationship is accounted for through the latent variable of Environ (see Table 2). This result indicates that relation between depression and obesity may be gender dependent. Therefore, we used SEM to assess the relation between BMI and depression separately for males and females. From the total sample of 12,376 respondents there were 5,660 males and 6,716 females. In subgroup analysis, Model 3 fit very well to the male group (Figure 2) with the goodness of fit indices of RMSEA $=0.056$ and CFI $=0.890$. However, the same model was not appropriate for the female participants.

In searching for a suitable model for females we dropped the connection between stress management and depression and the arrow from BMI to depression because they were not statistically significant. In this final model (Figure 3) all estimates were indeed significant and the goodness-offit indices were at acceptable level; RMSEA $=0.038$ with $90 \% \mathrm{CI}=(0.028,0.048)$ and $\mathrm{CFI}=0.879$.

\section{Discussion}

This work is based on a cross-sectional dataset and we had no information about history of obesity and depression in the family, history of debilitating diseases in the family and household, and adverse childhood experiences. Therefore, any statistically significant relation between variables cannot necessarily indicate causality. In addition, while SEM may produce a well fitting model, it may not be unique and there can be other reasonable models for the same dataset. Limitations with the AMOS software did not allow for the use of appropriate sampling weights 
Table 2: Regression coefficients for Model 3

\begin{tabular}{lcccc}
\hline & Estimate & SE & CR* & P \\
\hline Phys.Activ $\leftarrow$ Environ & 1.053 & 0.101 & 10.387 & $<0.001$ \\
Stress M Environ & -0.548 & 0.044 & -12.420 & $<0.001$ \\
BMI $\leftarrow$ Environ & 1.738 & 0.256 & 6.781 & $<0.001$ \\
Depression $\leftarrow$ Environ & -0.963 & 0.141 & -6.821 & $<0.001$ \\
BMI $\leftarrow$ Phys.Activ & -0.252 & 0.021 & -11.859 & $<0.001$ \\
Depression $\leftarrow$ Stress $M$ & 0.274 & 0.034 & 8.091 & $<0.001$ \\
SES Environ & 1.000 & & & $<0.001$ \\
Gender Environ & -0.600 & 0.048 & -12.385 & 0.015 \\
BMI $\leftarrow$ Depression & -0.282 & 0.116 & -2.439 & $<0.001$ \\
Depression $\leftarrow$ BMI & 0.150 & 0.045 & 3.359 & \\
\hline
\end{tabular}

* Critical ratio (the estimate divided by its standard error)

for estimations and modeling. Nevertheless, this modeling has generated some useful conclusions which may be used to inform future studies.

Although BMI is not a direct measure of body fat or lean tissue, it is the most widely investigated indicator of health problems associated with under-weight and overweight statuses. However, BMI as an indicator of risk may have limitations for individuals or populations who are very tall or very short or who have very long or short limb lengths in relation to trunk measurement [35].
Results of this analysis indicate that BMI and depression are associated and that this relation is gender dependent which is supported by some other studies [36,37]. In general, it can be concluded that higher BMI may result in more severe forms of depression (see Table 2) which is consistent with some other recent findings [11,12]. On the other hand, the same conclusion may not be drawn for the effect of depression on BMI, therefore, a more severe form of depression may not result in more weight gain. The subgroup analysis based on gender showed that in males the higher BMI is related to the more severe form

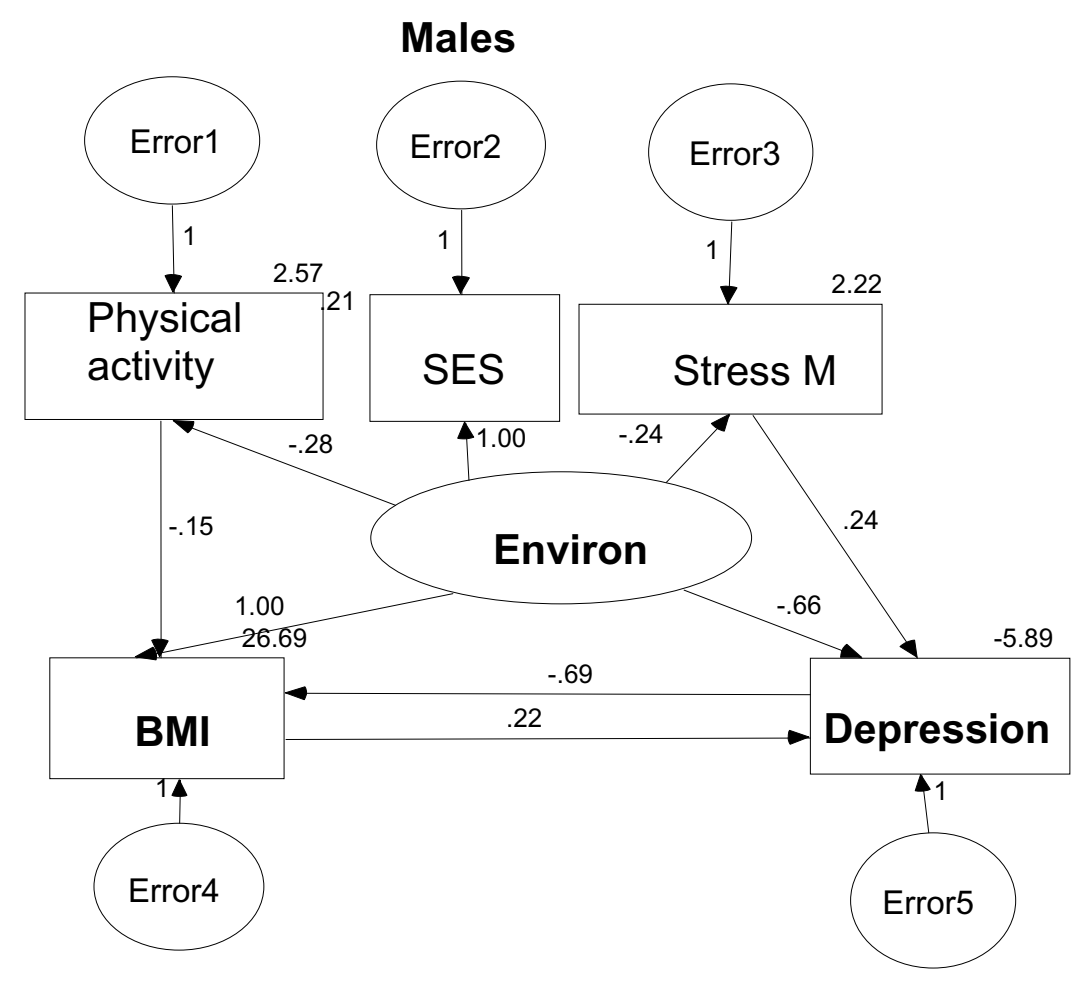

Figure 2

SEM model for male participants (Stress $M=$ Stress Management). 


\section{Females}

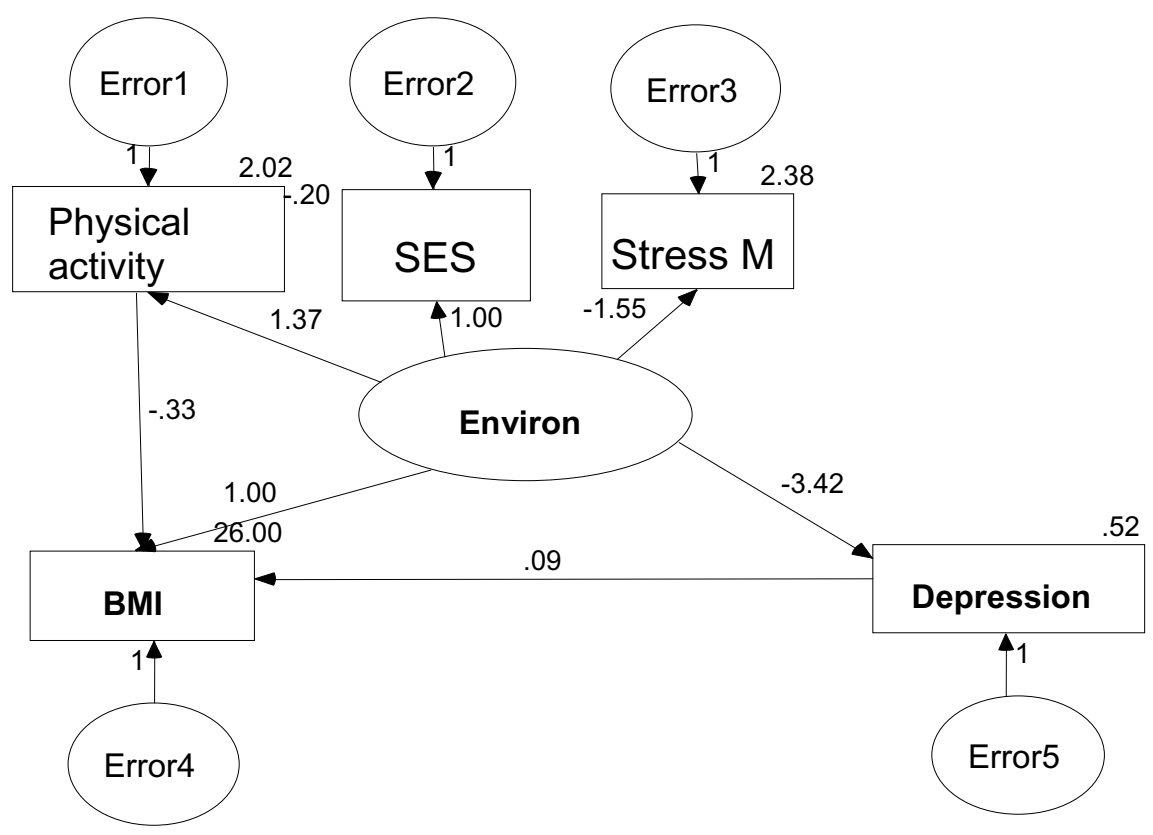

Figure 3

SEM model for female participants (Stress $M=$ Stress Management).

of depression, and the higher is the level of depression the lower is the BMI. These seemingly contradictory results about the relation between BMI and depression are in accordance with studies conducted by Palinkas et al. [13] and Stewart and Brook [14] and show the ability of the SEM method to differentiate directions of effects in a complicated modeling procedure. A possible explanation might be that new medications used to treat patients with depression have reduced/no weight gain side effect when compared to previous treatment options. However this is only a hypothesis as information regarding the treatment of these respondents was not available.

Another important result is the negative relationship between physical activity and BMI, which translates into "more physical activity - less weight problems". Model 3 also indicated that stress management had a direct relation with depression. The high score on the stress management means less ability to handle stress, indicating that individuals with reduced ability to handle stress suffer more from depression. The same relation was seen when males were analysed separately from females.

Among females stress management did not indicate a direct relation with depression and the path from obesity to depression was not statistically significant. In addition, the analysis did not show any relation between eating habits and relatives with depression and the outcome variables of BMI and depression. This lack of relationship may be explained by the large numbers of missing values in the variables of eating habits and relatives with depression.

In conclusion, this work shows that SEM can be used as an appropriate method to disentangle the complexity of the relation between obesity and depression. Further research is needed to better understand the structure of such complexity. Interestingly, this work showed that obesity and depression are associated but the form of the relation is different among males and females.

\section{Competing interests}

The author(s) declare that they have no competing interests.

\section{Authors' contributions}

Both authors contributed equally in designing the study and drafting the manuscript. The analysis was carried out by AD.

\section{Acknowledgements}

We are thankful to Amanda Bradford-Janke for editing the final version of the manuscript. 


\section{References}

I. Faith MS, Matz PE, Jorge MA: Obesity - depression associations in the population. Journal of Psychosomatic Research 2002, 53:935-942.

2. National Heart Lung and Blood Institute: Clinical guidelines for the identification, evaluation, and treatment of overweight and obesity in adults: the evidence report. 1998 [http:// www.nhlbi.nih.gov/guidelines/obesity/ob home.htm]. Ref Type: Electronic Citation

3. Schulz R, Beach SR, Ives DG, Martire LM, Arivo AA, Kop WJ: Association between depression and mortality in older adults: the Cardiovascular Health Study. Arch Intern Med 2000 160:1761-1768.

4. Anderson RJ, Freedland KE, Clouse RE, Lustman PJ: The prevalence of comorbid depression in adults with diabetes: a meta-analysis. Diabetes Care 200I, 24:1069-1078.

5. Pohjasvaara T, Vataja R, Leppavuori A, Kaste M, Erkinjuntti T: Depression is an independent predictor of poor long-term functional outcome post-stroke. European Journal of Neurology 200I, 8:315-319.

6. Robbins J, Hirsch C, Whitmer R, Cauley J, Harris T: The association of bone mineral density and depression in an older population. J Am Geriatr Soc 200I, 49:732-736.

7. Koenig HG, George LK, Larson DB, McCullough ME, Branch PS, Kuchibhatla $M$ : Depressive symptoms and nine-year survival of I,00I male veterans hospitalized with medical illness. American Journal of Geriatric Psychiatry 1999, 7:124-131.

8. Abramson J, Berger A, Krumholz HM, Vaccarino V: Depression and risk of heart failure among older persons with isolated systolic hypertension. Archives of Internal Medicine 200 I, I 6 I: I725-1730.

9. Faubel M: Body-Image and Depression in Women with Early and Late Onset Obesity. Journal of Psychology 1989, I 23:385-395.

10. Friedman MA, Brownell KD: Psychological correlates of obesity moving to the next research generation. Psychol Bull 1995, | | 7:3-20.

II. Roberts RE, Kaplan GA, Shema SJ, Strawbridge WJ: Are the obese at greater risk for depression? Am J Epidemiol 2000, I 52: I63-I70.

12. Roberts RE, Strawbridge WJ, Deleger S, Kaplan GA: Are the fat more jolly? Ann Behav Med 2002, 24: 169-180.

13. Palinkas LA, Wingard DL, Barrett-Connor E: Depressive symptoms in overweight and obese older adults: a test of the "jolly fat" hypothesis. J Psychosom Res 1996, 40:59-66.

14. Stewart AL, Brook RH: Effects of being overweight. Am J Public Health 1983, 73:171-178.

15. Goodman E, Whitaker E: A prospective study of the role of depression in the development and persistence of adolescent obesity. Pediatrics 2002, I I 0:497-504.

16. Pine DS, Goldstein RB, Wolk S, Weissman M: The association between childhood depression and adulthood body mass index. Pediatrics 200I, 107:1049-1056.

17. Dong C, Sanchez LE, Price RA: Relationship of Obesity to Depression: a Family-based Study. International Journal of Obesity 2004, 28:790-795

18. Rosmond R: Obesity and depression: same disease, different names? Medical Hypotheses 2004, 62:976-979.

19. Statistics Canada: Canada's population. Statistics Canada, retrieved from 2006 [http://www.statcan.ca/Daily/English/060927 d060927a.htm]. (November 22, 2006). Ref Type: Report

20. Statistics Canada: Canadian Community Health Survey, Cycle I.2. 2004 [http://www.statcan.ca/english/freepub/82-617-XIE/meth ods.htm]. Ref Type: Electronic Citation

21. Byrne NM, Hills AP, Hunter GR, Weinsier RL, Schutz Y: Metabolic equivalent: one size does not fit all. I Appl Physiol 2005 99: I I I2-III9.

22. Spadano JL, Must A, Bandini LG, Dallal GE, Dietz WH: Energy cost of physical activities in I2-y-old girls: METvalues and the influence of body weight. Int J Obes Relat Metab Disord 2003, 27:1528-1533

23. Krieger N, Williams DR, Moss NE: Measuring social class in US public health research: Concepts, methodologies, and guidelines. Annual Review of Public Health 1997, 18:341-378.

24. Wagstaff $A$, Watanabe $N$ : What difference does the choice of SES make in health inequality measurement? Health Economics 2003, I 2:885-890.
25. Nasser M: The EAT speaks many languages: review of the use of the EAT in eating disorders research. Eat Weight Disord 1997, 2:174-181.

26. Ullman JB: Structural Equation Modeling. In Using Multivariate Statistics Edited by: Tabachnick BG, Fidell LS. Boston: Allyn and Bacon; 1996:653-77|.

27. Browne MW, Cudeck R: Alternative ways of assessing mode fit. In Testing Structural Models Edited by: Bollen KA, Long JS. Newbury Park: Sage Publications; 1993

28. Kline RB: Principles and Practice of Structural Equation Modeling 2nd edition. New York: The Guilford Press; 2005.

29. Hu LT, Bentler PM: Cutoff criteria for fit indices in covariance structure analysis: Conventional criteria versus new alternatives. Structural Equation Modeling: A Multidisciplinary Journal 1999 , 6: $1-55$.

30. Byrne BM: Structural Equation Modeling with Amos. Basic concepts, Applications and Programming Mahwah, New Jersey: Lawrence Erlbaum Associates; 2001.

31. Stunkard AJ, Faith MS, Allison KC: Depression and obesity. Biological Psychiatry 2003, 54:330-337.

32. Kendler KS, Walters EE, Neale MC, Kessler RC, Heath AC, Eaves LJ: The structure of the genetic and environmental risk factors for six major psychiatric disorders in women: Phobia, generalized anxiety disorder, panic disorder, bulimia, major depression, and alcoholism. Arch Gen Psychiatry 1995 , 52:374-383.

33. Dehghan M, Akhtar-Danesh N, Merchant AT: Childhood obesity, prevalence and prevention. Nutr J 2005, 4:24.

34. Hu LT, Bentler PM: Cutoff criteria for fit indices in covariance structure analysis: Conventional criteria versus new alternatives. Structural Equation Modeling: A Multidisciplinary Journal 2006, 6:1-55.

35. Health Canada: Canadian guidelines for body weight classification in adults. 2003 [http://www.hc-sc.gc.ca/fn-an/alt formats/hpfbdgpsa/pdf/nutrition/weight book-livres des poids e.pdf]. Ref Type: Electronic Citation

36. Carpenter KM, Hasin DS, Allison DBeal: Relationships between obesity and DSM-IV major depressive disorder, suicide ideation and suicide attempts:results from a general population study. Am J Public Health 2000, 90:25I-257.

37. Istvan J, Zavela K, Weidner G: Body weight and psychological distress in NHANES I. Int J Obes 1992, 16:999-1003.

\section{Pre-publication history}

The pre-publication history for this paper can be accessed here:

http://www.biomedcentral.com/1471-2288/7/17/prepub

Publish with BioMed Central and every scientist can read your work free of charge

"BioMed Central will be the most significant development for disseminating the results of biomedical research in our lifetime. "

Sir Paul Nurse, Cancer Research UK

Your research papers will be:

- available free of charge to the entire biomedical community

- peer reviewed and published immediately upon acceptance

- cited in PubMed and archived on PubMed Central

- yours - you keep the copyright 